\title{
China's export evolution in the dynamic global product space from 2000 to 2011
}

\author{
Shan $\mathrm{Li}^{1}$, Xun Li ${ }^{1{ }^{* *}}$, Haohui Chen ${ }^{2,3}$ and Wei Lang ${ }^{1}$ \\ ${ }^{1}$ School of Geography and Planning, Urbanization Institute, and China Regional Coordinated Development and Rural Construction Institute, \\ Sun Yat-Sen University, No. 135 Xingang West Road, Guangzhou, 510275, China \\ ${ }^{2}$ Commonwealth Scientific and Industrial Research Organisation, Goods Shed Village Street, Docklands Vic 3008, Australia \\ ${ }^{3}$ Faculty of Information Technology, Monash University, Clayton VIC 3800, USA
}

\begin{abstract}
China's massive export trajectory can enlighten many developing countries regarding foreign trade. Based on the 'product space' theory, the present study analyses the evolution of China's export economy from three perspectives: (1) comparative advantage from a longitudinal perspective, (2) diversification from a horizontal perspective, and (3) location in dynamic global product space from a spatial perspective. Results show that China's export economy is becoming more diversified and has evolved from a polarized structure to a relatively balanced system. At the same time, China has been moving from a peripheral location to a core place in the clusters of global product space. This study concludes that both path dependence and path creation are important in driving China's export evolution process.
\end{abstract}

Keywords: Developing countries, export evolution, foreign trade, global product space, path creation, path dependence.

CHINA has performed a growth miracle over the past four decades. In the context of globalization, China's export success is more important to economic performance than ever before ${ }^{1,2}$. The country's share of world trade has increased from $4.3 \%$ to $10.4 \%$ since joining the World Trade Organization. In recent years, China has become the world's largest exporter and its export growth rate has also become the fastest in the globe. China's increasing footprint in foreign trade and investment in all the major aggregates are evident to the world ${ }^{3}$. It may be necessary for other developing countries to draw lessons from the experiences of China's export evolution. The expansion of markets has brought about specialized division of labour and foreign trade, promoted the optimal allocation of resources, and upgraded the industrial structure ${ }^{4,5}$. The present study has mainly focused on analysing the quantity or structure of China's exported products ${ }^{6}$, while being less concerned with the evolution of its export position in the world. In particular, quantitative studies of the evolution mechanism are lacking. What should we focus on when we study the evolution of exports?

*For correspondence. (e-mail: lishan8@mail2.sysu.edu.cn)
Industrial evolution is a comprehensive upgrade process, including value upgrades and factor upgrades ${ }^{7}$. Many studies have concentrated on the changing characteristics of comparative advantages ${ }^{3}$, export diversity ${ }^{8}$, industry structure ${ }^{9}$ and industry clusters ${ }^{10}$. Evolutionary economic geographers are interested in determining how a region develops a particular economic landscape.

The objective of the present study is to explore China's export pattern and the driving force behind it, aiming to provide reference for the industrial development of other developing countries and provide targeted policy guidance for promoting trade cooperation between China and other countries, especially under the 'One Belt, One Road' strategy.

This study quantitatively reveals the evolution path of China's export status in the global trade network based on 'product space' theory, which is different from the traditional qualitative analysis of industry development in China. Path dependence is usually the dominant force driving industrial development in most countries. However, this study has found that exogenous path-break force is as important as path dependence in China.

\section{Literature survey}

In the traditional literature, relevant research on China's industrial development mostly adopts a qualitative method. The small amount of quantitative research is limited to the description and analysis of China's export volume and structure over the years. An in-depth quantitative study of the country's evolutionary process in the global export trade network is relatively rare. Evolutionary economic geography has developed rapidly and become a new focus now. Path dependence is regarded as the primary rule of evolutionary economy ${ }^{11}$, which generally focuses on the historical process of regional development, and argues that the current and future development patterns are constrained and determined by the past conditions of any region ${ }^{12,13}$. Specific product clusters and industrial structure in a region have a significant effect on its future development trajectory ${ }^{13,14}$. The specific trade pattern of a region is because of the accumulated production capabilities which include technology, human capital, 
infrastructure, institutions and so on. Each new capability is somewhat related to a pre-existing one $e^{15,16}$, and this relatedness is emphasized. In other words, it means that a new product emerges near an existing product. There are many ways to measure relatedness ${ }^{17,18}$, reflected in different dimensions such as cognitive, organizational, social, institutional and geographical aspects ${ }^{19,20}$.

In recent years, a new and popular measurement of relatedness between pairs of products has been proposed in the product space theory by Hidalgo et $a .^{21}$, which is outcomes-based and can integrate all dimensions. It is measured by the minimum probability of two advantaged products being exported together by the same country, which is a co-occurrence concept called 'proximity'. Advantaged product means one country's export level is higher relative to the global average. The product space theory can study and visualize scientifically the proximities of products. It implies that the closer the two products are in the product space, easier it is for one country already exporting one product to export the other product, assuming that the capabilities of exporting one facilitate export of the other. Related research provides a novel perspective on industrial development ${ }^{22,23}$. Many studies have followed this ideology in different regions, including Brazil $^{24}$, Sub-Saharan Africa ${ }^{8}$ and Indonesia ${ }^{25}$. Researchers are interested in the evolutionary paths in a region to help understand the growth mechanism. They consider that new industries related to existing ones are driven by the effective power of path dependence ${ }^{26,27}$. While for new products irrelevant to the pre-existing advantaged products, they question how these came about. Such products appear to be generated by a different path relying only on exogenous forces ${ }^{28}$, that is, path creation. It includes many complex aspects like creative destruction in productive technology $\mathrm{y}^{29,30}$, intra-regional links ${ }^{31,32}$ and government intervention ${ }^{33,34}$.

This study analysed China's export evolution based on product space theory from three perspectives: comparative advantage from a longitudinal perspective, diversification from a horizontal perspective, and location in global product space from a spatial perspective. The evolution path of China's exports was analysed, aiming to characterize the evolution of its export-oriented economy over time and to provide a reference for developing countries.

The gap that this study fills in the mainstream literature is mainly reflected in two aspects. First, geography has studied the literature of Chinese trade mainly to analyse differences in the export structure between China's internal regions on the regional scale, and rarely involves the horizontal comparison between China and other countries on a national scale, lacking the analysis of the country's export location in the global trade pattern. Secondly, most of the existing research does not consider the correlation between industries, ignores the nature of path dependence under the perspective of evolution, and lacks scientific analysis of the development path of China's export industry. The present study explores China's export location, export pattern and evolution path under evolutionary economy from a global perspective, which enriches the existing mainstream literature.

\section{Data and methods}

This study uses International Trade Data coded in the harmonized commodity description and coding systems (HS-6) for the period from 2000 to 2011. Data for 2000 were extracted from the 'World Trade Flows: 19622000' dataset which were collected and processed by Feenstra, Lipsey, Deng, Ma, \& Mo's et al., while data from 2001 to 2011 were extracted from the United Nations COMTRADE database.

\section{Revealed comparative advantage}

Revealed comparative advantage (RCA) measures one country's export level relative to the global average. Let $x(c, i)$ be the total export value of product $i$ by country $c$. When $\mathrm{RCA}_{c, i}>1$, country $c$ exports more of product $i$ as a share of its total exports than the global 'average'. A product with RCA $>1$ is considered as a country's advantaged product.

$$
\operatorname{RCA}_{c, i}=\frac{x(c, i)}{\sum_{i} x(c, i)} / \frac{\sum_{C} x(c, i)}{\sum_{c, i} x(c, i)} .
$$

\section{Proximity}

The similarity accumulated production capabilities of products influences the relatedness between two products. The more closely related two products are, the easier it is for a country to develop them together, that is, a country can easily develop new products when the closely related

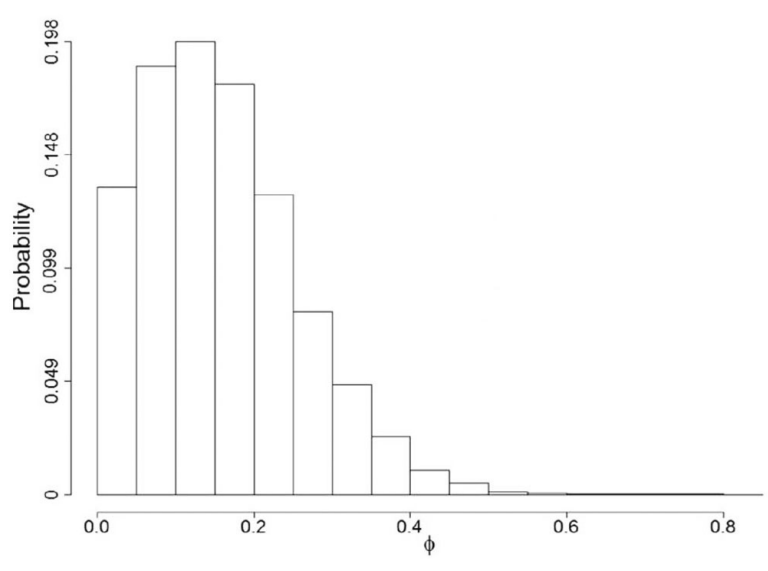

Figure 1. Density distribution of the proximity of global products. 


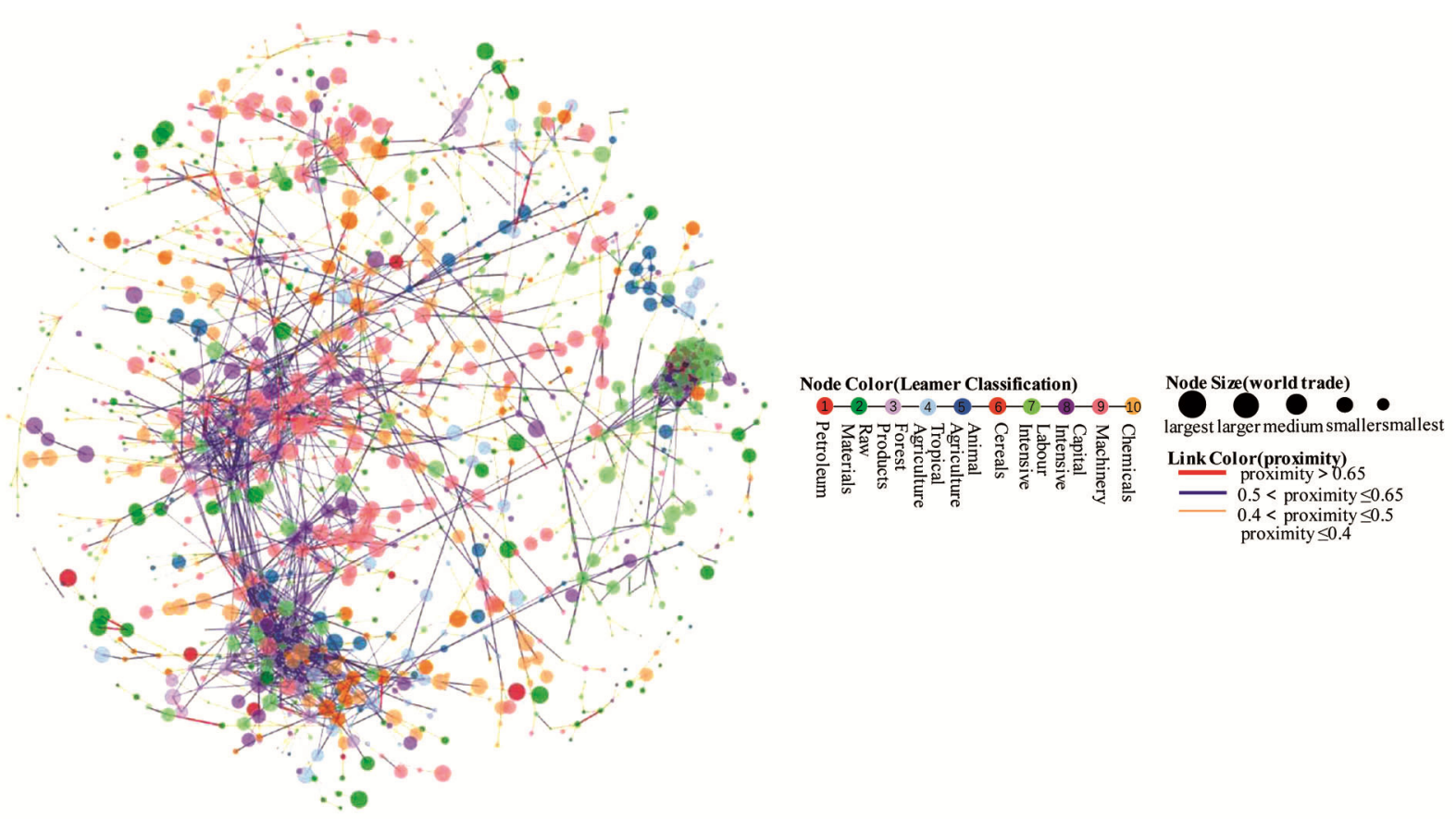

Figure 2. Global product space for the year 2011. Each node represents an export product. Node size indicates the global trade value of the product. Node colour represents the product type classified using Leamer Classification. Links are colour coded with their proximity.

ones already have an advantage. For example, the ability to export apples may include more of the conditions suitable to export pears than export furniture, because of production necessities such as soil, climate and skilled agronomists. The ability to export apples is quite different from the ability to export furniture. So the proximity of apples and pears is higher than that of apples and furniture.

Proximity $\phi_{i, j}$ between products $i$ and $j$ is the minimum of the pairwise conditional probabilities of a country exporting one product, given that it exports the other. A closer proximity indicates a higher correlation between two products and a closer spacing. The value of $\phi_{i, j}$ is between 0 and 1 (Figure 1)

$$
\phi_{i, j}=\min \left\{P\left(\mathrm{RCA}_{x_{i}} \mid \mathrm{RCA}_{x_{j}}\right), P\left(\mathrm{RCA}_{x_{j}} \mid \mathrm{RCA}_{x_{i}}\right)\right\} .
$$

\section{Product space}

First, we generate an $N * N$ proximity matrix ( $N$ represents the total product types in the world). Then we construct an original product network to visualize the proximity between products based on the matrix. This network contains too much information, including all links between products, even for unrelated pairs. In this case, the rough network can hardly reveal the correlation structure of the products. To display the structure clearly, we use a maximum spanning tree based on Hidalgo to generate the skeleton of the network. $\phi \leq 0.5$ denotes that two products being exported simultaneously is a random occurrence and only $\phi>0.5$ denotes that the two products are related. For better visualization, we use a force-spring algorithm to clarify the layout.

Figure 2 illustrates the global product space for 2011. The network includes three main clusters: the 'light industry cluster' composed of green nodes, including labour-intensive categories like shoes and handbags, among others; the 'mechanical equipment cluster' composed mainly of purple and orange-red nodes, including technology-intensive steel and office electronics, among others, and the 'integrated chemical cluster' composed mainly of orange and light purple nodes, relatively mixed and mainly consisting of chemical products. The network shows that the proximities in the light industry cluster are the greatest $(\phi>0.65)$, followed by the mechanical equipment and integrated chemical clusters $(0.5<\phi \leqslant$ $0.65)$. Nearly all the proximities in the periphery are less than 0.55 . The whole network has a heterogeneous structure.

\section{Evolution of China's comparative advantage and diversification in export}

We analyse China's comparative advantage using ranksize distributions (Figure 3). We find that the slopes of the best-fit lines for 2000, 2005 and 2011 are 1.50, 1.38 and 1.30 respectively, indicating that gaps in the RCA have gradually decreased. This implies that China has focused on the production of a limited number of dominant advantaged products in the past, which has resulted 
RESEARCH ARTICLES

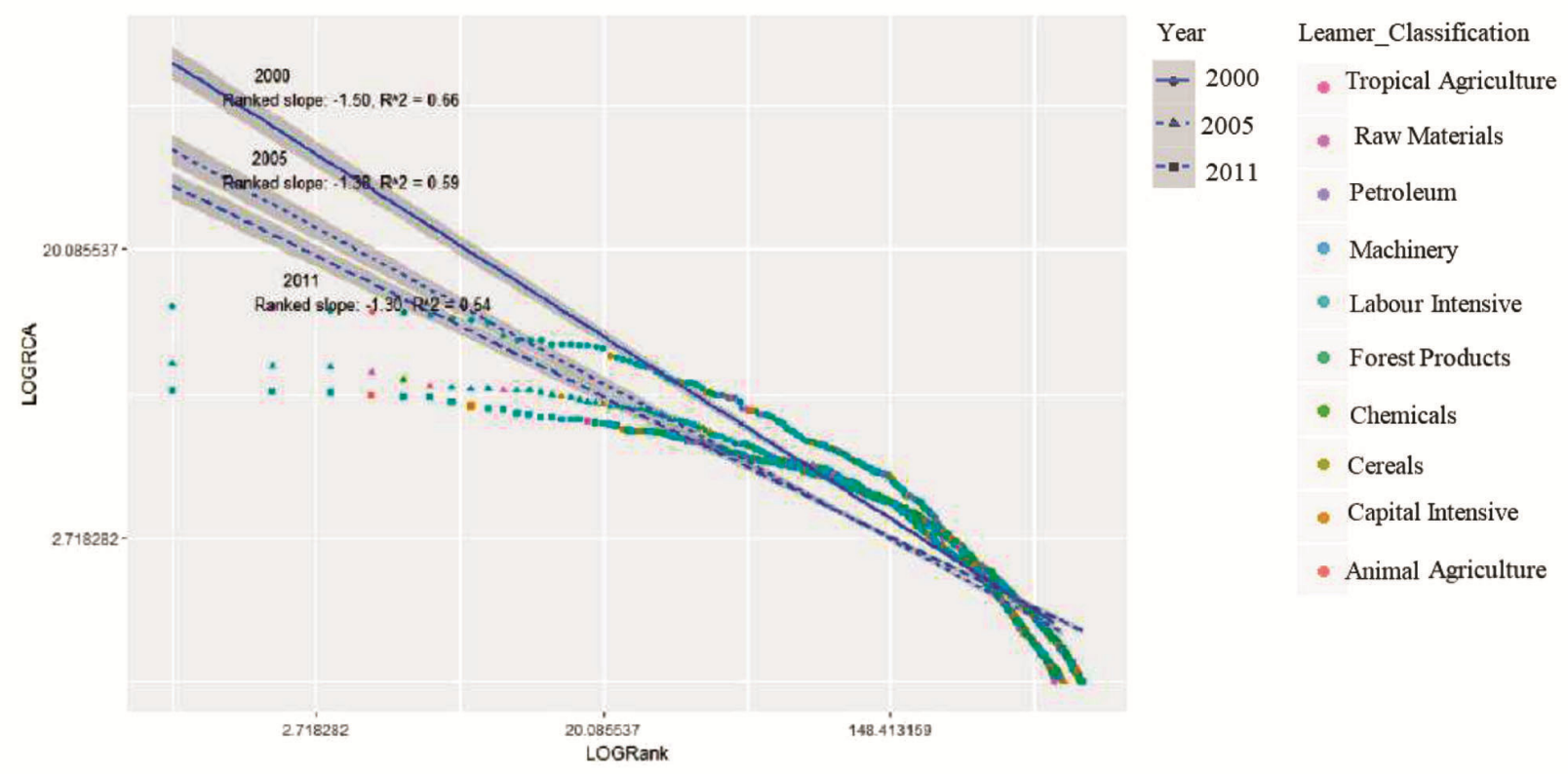

Figure 3. Rank-size distribution of the revealed comparative advantage (RCA) of China's exports in 2000, 2005 and 2011. The horizontal axis represents the logarithm of the rankings, and the vertical axis represents the RCA of China's advantaged export products.

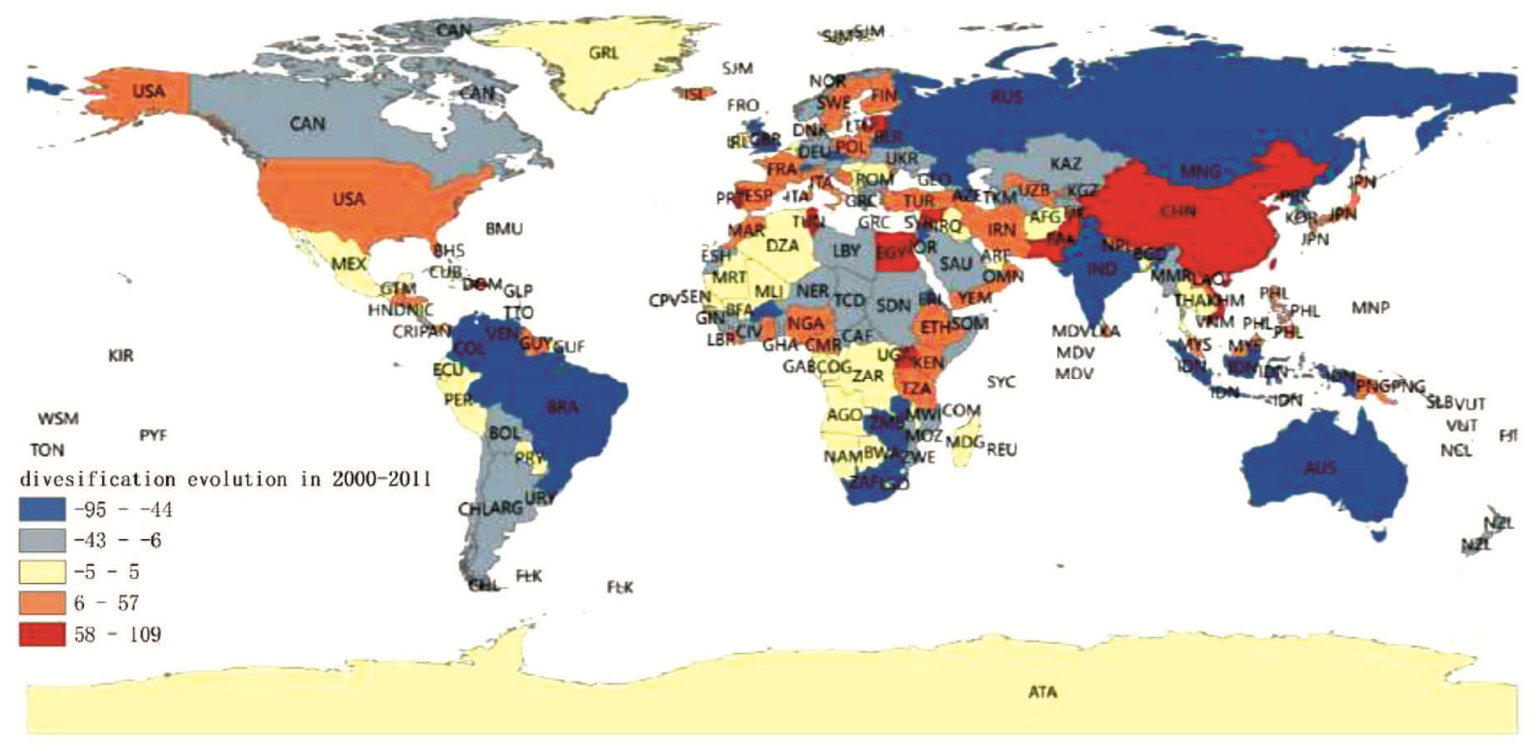

Figure 4. Diversification evolution of all countries from 2000 to 2011.

in the polarized trade pattern. In contrast, in recent years, China's exports have become increasingly balanced, which indicates that the country has begun to pay attention to improving the competitiveness of general superior products. China has begun to enter a new stage of industrial evolution ${ }^{35}$.

Some studies have measured diversification using the number of exports with RCA $\geqslant 1$. We followed this measurement and found that China's diversification was among the top 10 in the world in 2000 as well as 2011, and has steadily increased (Figure 4). China exported 465 advantaged products in 2000 and 565 in 2011. The global rank of China's diversification index has jumped from seventh to second in the 12 intervening years. The most diversified countries have always been Germany and Italy. The growth rate of China's diversification has been obvious, which shows that the country has committed to integrating itself into the world economic system in recent years.

We found that even though labour-intensive products dominated China's export basket, its share of all advantaged products decreased from $42.37 \%$ in 2000 to $40.53 \%$ 
(a) Global Space in 2000

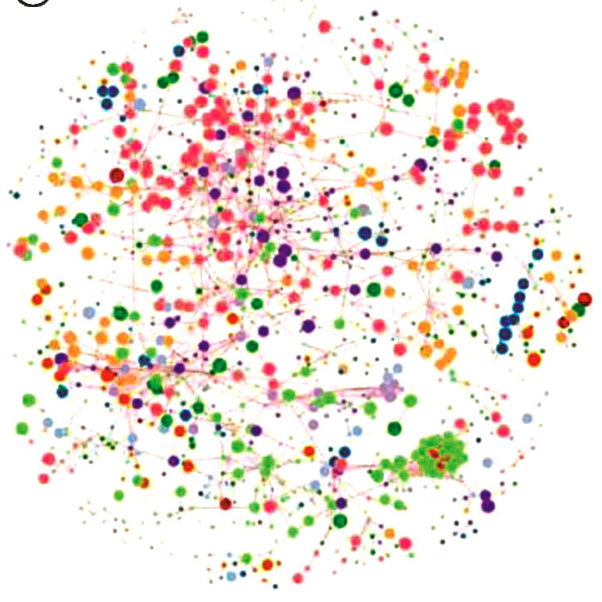

(c) Global Space in 2005

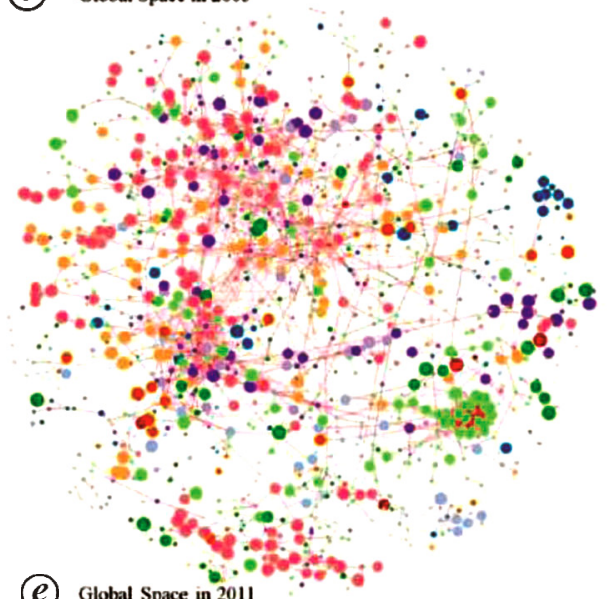

(e) Global Space in 2011
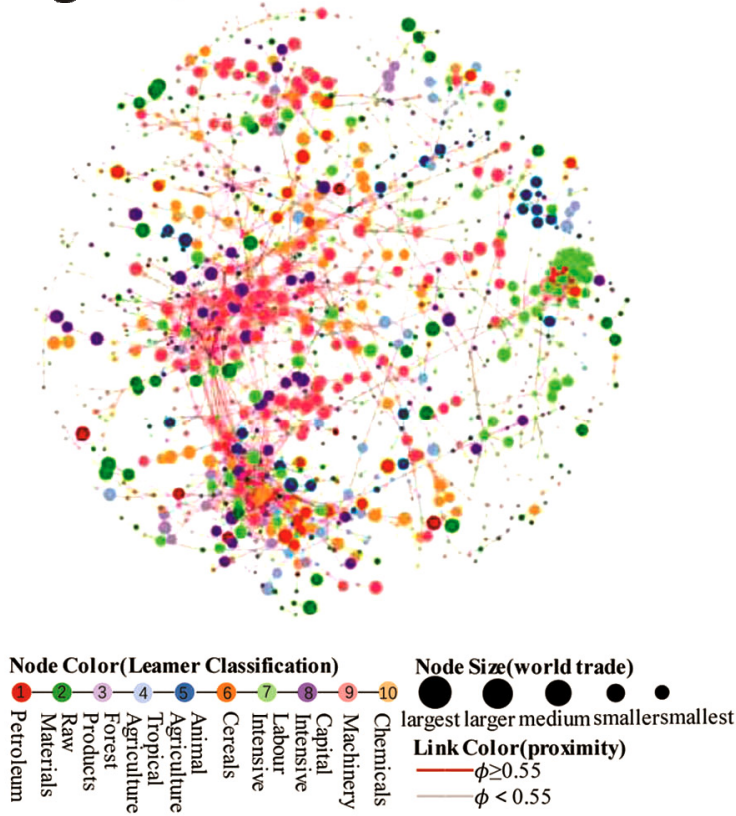

(b) China's Position in 2000

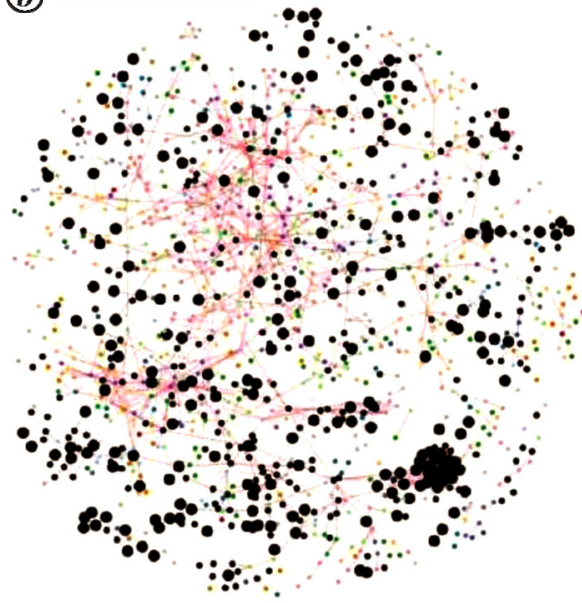

(d) China's Position in 2005

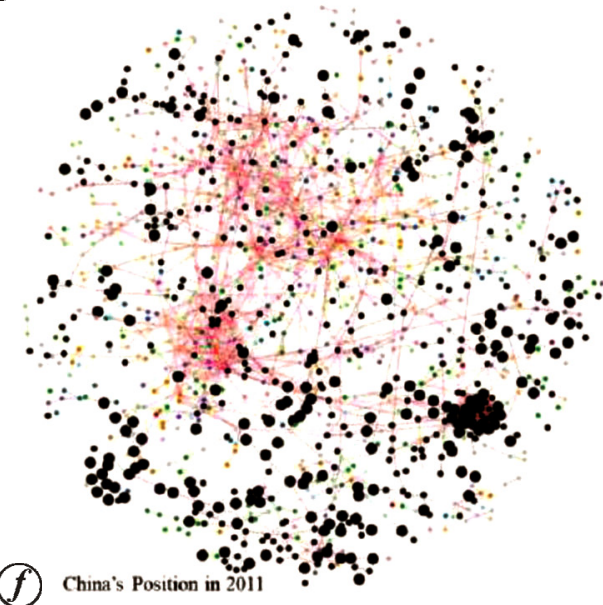

$\rightarrow \therefore$
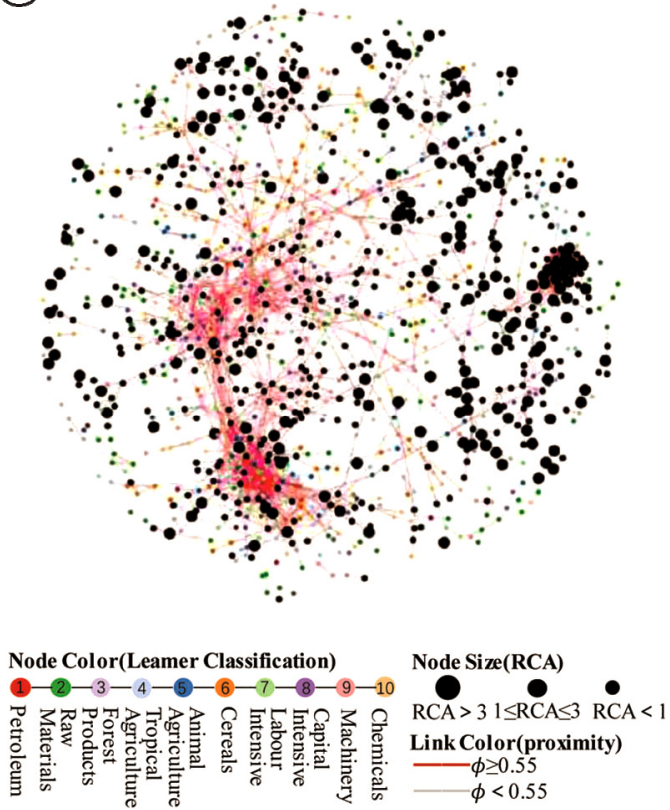

Figure 5. Global dynamic product space and China's location evolution in 2000, 2005 and 2011. (a), (c), and (e) represent the global product space in 2000, 2005 and 2011, respectively. Node colour represents the product type, and node size shows the global trade value. $(\boldsymbol{b}),(\boldsymbol{d})$, and $(\boldsymbol{f})$ represent the location of China's advantaged products in the corresponding global product space. Black nodes denote the advantaged products and node size indicates the degree of China's advantage. 
in 2011. In addition, the number and proportion of advantaged products in machinery, chemical, and capitalintensive industries sustained growth momentum, while those of advantaged products in animal products, cereals and raw materials continued to decrease. China has spared no effort to improve advanced technology to increase the export of technology-based and capitalintensive industries, and to weaken its emphasis on resource-intensive industries ${ }^{36}$.

\section{Evolution of China's location in global dynamic product space}

In this study we constructed the global product space for 2000, 2005 and 2011 (Figure 5 $a, c$ and $e$ respectively). We calculated the respective closeness of the networks to measure the compactness of the topological structure. Closeness $_{i}$ is defined as the centrality of a vertex $i$ by the inverse of the average length of the shortest paths to all the other vertices in the graph. We found that the average closeness of all nodes in the networks become greater over time, and the changing tendency was especially

Table 1. Closeness of the network structure

\begin{tabular}{ccc}
\hline Year & $\begin{array}{c}\text { Average closeness of } \\
\text { all products }\end{array}$ & $\begin{array}{c}\text { Maximum closeness } \\
\text { of products }\end{array}$ \\
\hline 2000 & 0.191 & 0.303 \\
2005 & 0.221 & 0.344 \\
2011 & 0.227 & 0.353 \\
\hline
\end{tabular}

Table 2. Closeness of China's advantaged products

\begin{tabular}{llll}
\hline & 2000 & 2005 & 2011 \\
\hline $\begin{array}{c}\text { Average closeness of all products } \\
\begin{array}{c}\text { Average closeness of products of } \\
\text { dominant advantage (PDA) }\end{array}\end{array}$ & 0.178 & 0.205 & 0.217 \\
$\begin{array}{c}\text { Average closeness of products } \\
\text { of general advantage (PGA) }\end{array}$ & 0.184 & 0.184 & 0.195 \\
\hline
\end{tabular}

Table 3. Evolution of China's PDA from 2000 to 2011

\begin{tabular}{lrrrrr}
\hline & & & & $2000-$ & $2005-$ \\
Leamer classification & 2000 & 2005 & 2011 & 2005 & 2011 \\
\hline Petroleum & 1 & 0 & 0 & -1 & 0 \\
Raw materials & 15 & 9 & 10 & -6 & 1 \\
Forest products & 5 & 5 & 5 & 0 & 0 \\
Tropical agriculture & 8 & 4 & 2 & -4 & -2 \\
Animal products & 6 & 2 & 2 & -4 & 0 \\
Cereals & 2 & 1 & 0 & -1 & -1 \\
Labour-intensive & 112 & 106 & 111 & -6 & 5 \\
Capital-intensive & 18 & 17 & 23 & -1 & 6 \\
Machinery & 29 & 26 & 31 & -3 & 5 \\
Chemicals & 10 & 6 & 7 & -4 & 1 \\
Total & 206 & 176 & 191 & -30 & 15 \\
\hline
\end{tabular}

obvious from 2000 to 2005. This indicates that the structure of the network is progressively more compact (Table 1). The connected lines in the three networks also became denser, indicating that the products become increasingly closely related.

$$
\text { Closeness }_{i}=\frac{N-1}{\sum_{k=1}^{N} d\left(p_{i}, p_{k}\right)} .
$$

We further divided the products into three groups according to the corresponding RCA values. Those with $\mathrm{RCA} \geqslant 3$ are called products of dominant advantage (PDA), the ones with $1 \leqslant \mathrm{RCA}<3$ are called products of general advantage (PGA), and those with $\mathrm{RCA}<1$ are called products of null advantage (PNA). We found the average closeness of all China's advantaged products was $0.178,0.205$, and 0.217 in 2000, 2005, and 2011 respectively, showing that the value progressively increased over time. The average closeness of China's PDA and PGA had the same changing tendency (Table 2). This indicates that China's advantaged products, especially PGA, are increasingly migrating to the network core.

Evolution of China's location in the global product space: In 2000, China's PDA in the labour-intensive, machinery and raw materials categories spread into the periphery, and only some capital-intensive products were scattered evenly in the core area. In case of PGA, most were labour-intensive and located on the periphery (Figure $5 b$ and Tables 3 and 4). Compared with 2000, China's PDA changed moderately in 2005. The number of PGA increased between 2000 and 2005, and products in the capital-intensive and chemicals categories began to emerge; these were mainly located at the core (Figure $5 d$ and Tables 3 and 4). Compared with 2005, the number of China's PDA increased in 2011, except in tropical agriculture and cereals. Although labour-intensive products still dominated, growth of the capital-intensive category was pivotal and not to be ignored. For China's PGA,

Table 4. Evolution of China's PGA from 2000 to 2011

\begin{tabular}{lrrrcc}
\hline & & & & $2000-$ & $2005-$ \\
Leamer classification & 2000 & 2005 & 2011 & 2005 & 2011 \\
\hline Petroleum & 1 & 2 & 2 & 1 & 0 \\
Raw materials & 22 & 23 & 20 & 1 & -3 \\
Forest products & 6 & 7 & 14 & 1 & 7 \\
Tropical agriculture & 15 & 16 & 17 & 1 & 1 \\
Animal products & 16 & 13 & 11 & -3 & -2 \\
Cereals & 9 & 5 & 3 & -4 & -2 \\
Labour-intensive & 85 & 108 & 118 & 23 & 10 \\
Capital-intensive & 29 & 42 & 49 & 13 & 7 \\
Machinery & 38 & 55 & 79 & 17 & 24 \\
Chemicals & 38 & 48 & 61 & 10 & 13 \\
Total & 259 & 319 & 374 & 60 & 55 \\
\hline
\end{tabular}



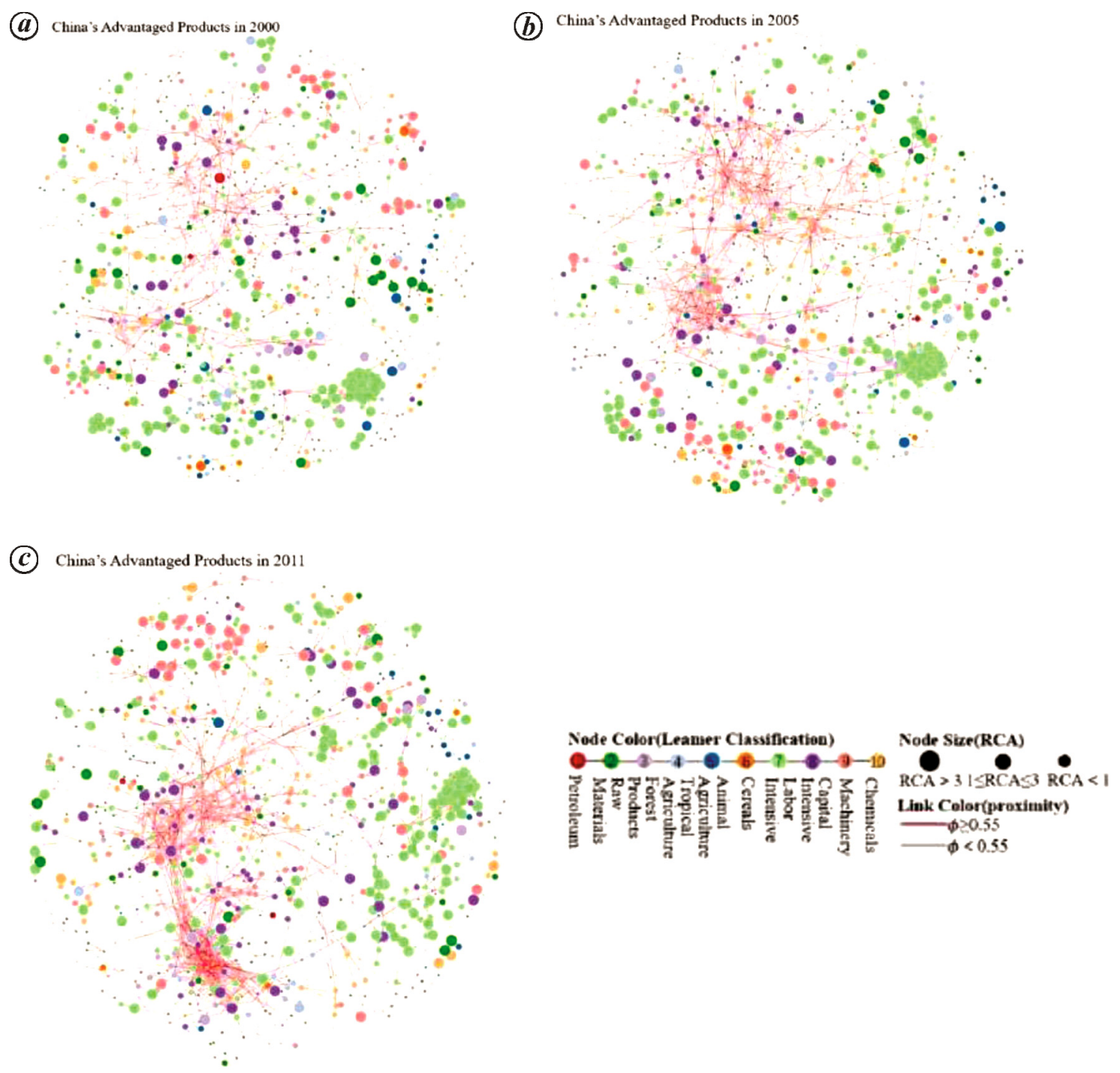

Appendix 1. China's advantaged products in 2000, 2005 and 2011.

machinery products were growing rapidly, and capitalintensive products and chemicals, which were mainly located at the core, continued their growth trend (Figure $5 f$ and Tables 3 and 4).

Evolution of the coupling relationship between China's advantaged products and global high-value products: In 2000, China's PDA were not among those with the highest trade values in the world, except for the labourintensive products on the periphery. This indicates that the country occupied an inferior position in global trade. In 2005, China's PDA was still not highly correlated with products having high trade value in the world, but the situation had improved slightly (see Appendix 1). In 2011, the overlaps between China's PDA and products with high global trade values had clearly increased. In addition to the labour-intensive and machinery products in the periphery, the overlapping products included the capital- intensive ones at the core. China has now emerged with advantaged products in the capital-intensive, machinery and chemical industries. Increasing numbers of China's advantaged products have been consistent with the products of high trade value in the world.

\section{Path dependence or path creation for China's export evolution}

Path dependence: In order to examine whether the products that were upgraded were subject to endogenous path dependence, we first constructed a proximity matrix composed of 83 new advantaged products emerging in 2005 and 465 existing advantaged products in 2000 . If the proximity $\phi \geq 0.5$, we considered the corresponding new product as a 'path-dependent' product and the links 'paths'. In 2005, there were 26 'paths' linking with 16 
(a) Path dependence Matrix in 2005

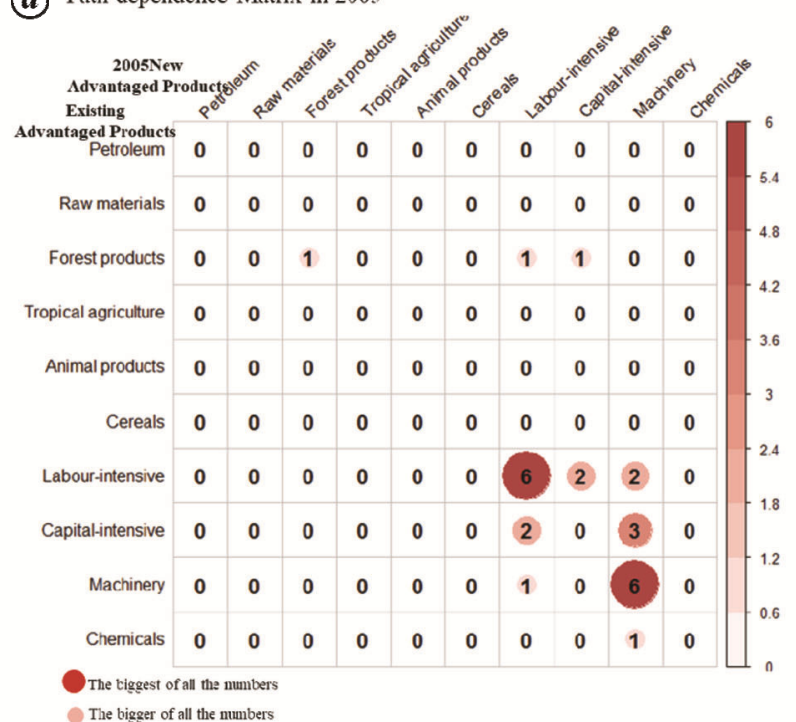

(c)

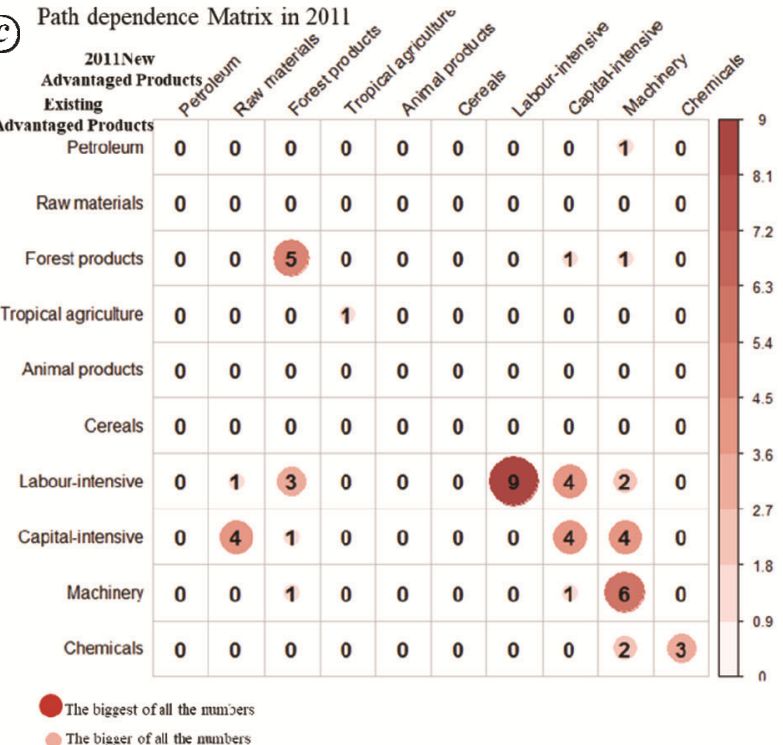

(b) Position of "path-dependence" products in 2005

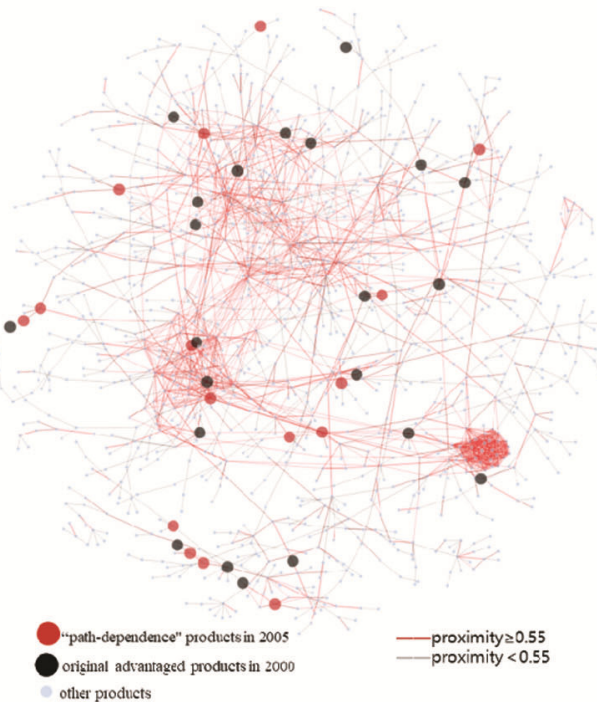

(d) Position of "path-dependence" products in 2011

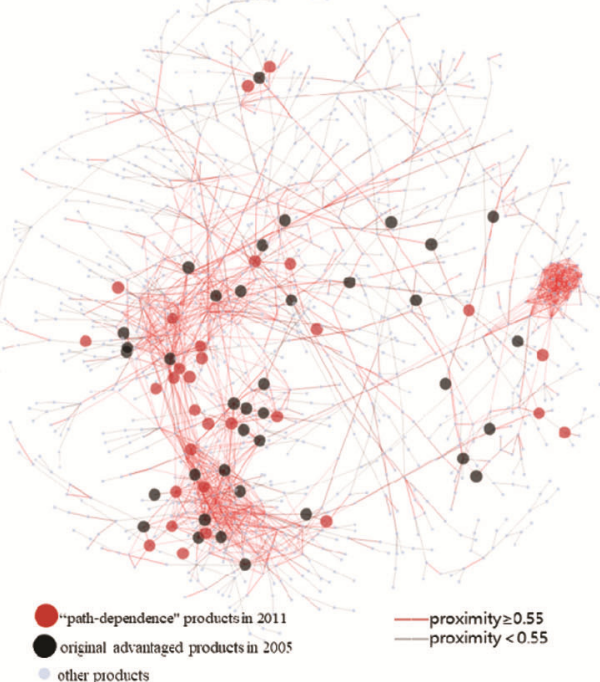

Figure 6. Path dependence mechanism during 2000-2005 and 2005-2011.

'path-dependent' products (one product was driven by several existing advantaged products together) (Figure $6 a$ ), with most located in the periphery (Figure $6 b$ ). In 2011, there were 54 'paths' linking with 30 'pathdependent' products (Figure $6 c$ ), and most of them were distributed near the three clusters (Figure $6 d$ ). We find that China's new products generated by endogenous force are increasing, and they tend to transfer gradually to the core area.

Path creation: If the proximity between new advantaged products and any existing advantaged products is less than 0.4 , the new products are considered driven by exogenous forces. We consider the corresponding new products as 'path-creation' products. In 2005, there were
20 'path creation' products (Table 5). Among these, the labour-intensive products were the most numerous. In 2011 , there were 20 'path-creation' products. The number of new chemical products in 2011 accounted for $11.11 \%$ of the number of existing advantaged chemical products in 2005. This is much greater than the ratio for products in other industries, suggesting that China's chemical industry has sustained it growth momentum.

Evolutionary economic geography considers that it is difficult for a new product to emerge without a historical basis. While comparing the number of new products driven by path dependence and path creation, we found that the exogenous forces of China could be crucial during its transition period. When strategic industries that have no advantage in the past are difficult to drive depending on 
Table 5. Statistics for 'non-path-dependence' products in 2005 and 2011

\begin{tabular}{|c|c|c|c|c|c|c|}
\hline \multirow[b]{2}{*}{ Industry } & \multicolumn{3}{|c|}{2005} & \multicolumn{3}{|c|}{2011} \\
\hline & $\begin{array}{l}\text { Number of new } \\
\text { products in } 2005\end{array}$ & $\begin{array}{c}\text { Number of advantaged } \\
\text { products in } 2000\end{array}$ & Ratio (\%) & $\begin{array}{l}\text { Number of new } \\
\text { products in } 2011\end{array}$ & $\begin{array}{c}\text { Number of advantaged } \\
\text { products in } 2005\end{array}$ & Ratio (\%) \\
\hline Petroleum & 0 & 2 & 0.00 & 1 & 2 & 50.00 \\
\hline Raw materials & 3 & 37 & 8.11 & 2 & 32 & 6.25 \\
\hline Forest products & 0 & 11 & 0.00 & 0 & 12 & 0.00 \\
\hline Tropical agriculture & 1 & 23 & 4.35 & 0 & 20 & 0.00 \\
\hline Animal products & 1 & 22 & 4.55 & 1 & 15 & 6.67 \\
\hline Cereals & 0 & 11 & 0.00 & 0 & 6 & 0.00 \\
\hline Labour-intensive & 8 & 197 & 4.06 & 3 & 214 & 1.40 \\
\hline Capital-intensive & 1 & 47 & 2.13 & 2 & 59 & 3.39 \\
\hline Machinery & 3 & 67 & 4.48 & 5 & 81 & 6.17 \\
\hline Chemicals & 3 & 48 & 6.25 & 6 & 54 & 11.11 \\
\hline
\end{tabular}

endogenous path dependence, they can call for the targeted regulation of the Chinese government to improve their development ${ }^{37}$.

\section{Conclusion}

This study highlights the evolution of China's exports between 2000 and 2011 based on a comprehensive analysis. The country's economic achievement has evolved sustainably and has developed a more diversified and sophisticated export basket. Labour-intensive industry has always dominated China's market, where the proportions of technology- and capital-intensive industries are increasing continuously, and primary industries have been decreasing annually. The country's foreign trade pattern has been shifting from a polarized structure to a relatively balanced system. Half of China's new advantaged products are generated by path creation.

This study also clearly reveals China's specific location in the global trade network. It can accurately provide a clear reference frame for the country to formulate product support policies and promote the development of strategic industries. Active government intervention and policy guidance play an important role in China. The country has adopted relatively aggressive path-breaking strategies to develop new advantaged products, which allow the economy to rapidly achieve export advantages for strategic products. It has improved the balance in the economy by promoting both its traditional low-end value products and high-end trade value products in the global market. China has developed a more diversified and balanced export basket, and gradually moved from periphery to core in the global product space. In recent years, China has been committed to the economic development model of 'quality and efficiency improvement', not only to increase economic growth rate but also to improve the quality of economic development. Therefore, we conclude that developing countries cannot completely rely on path dependence under the market mechanism, as they will easily fall into the 'low-end trap'. They need to promote the development of high-end industries with certain macro-government regulation. China's remarkable achievement in foreign trade has enlightened many other developing countries whose exports have always been placed at the periphery of the global product space.

1. Lang, W., Chen, T. and Li, X., A new style of urbanization in China: transformation of urban rural communities. Habitat Int. 2016, 55(1), 1-9.

2. Lall, S., The technological structure and performance of developing country manufactured exports, 1985-98. Oxford Dev. Stud., 2000, 28(3), 337-369.

3. Rodrik, D., What's so special about China's exports. China World Econ., 2006, 14(5), 1-19.

4. Boone, J., Competitive pressure: the effects on investments in product and process innovation. Rand J. Econ., 2000, 31(3), 549-569.

5. Zhou, M., Lu, Y. and Fu, D., Trade liberalization and industrial upgrading in China: facts and mechanisms. J. World Econ., 2016 , 10, 78-102.

6. Li, G. and Liu, J., Empirical analysis of international competitiveness of China's industry after a decade of WTO accession. Finance Trade Econ., 2012, 8, 88-96.

7. Ernst, D., Global production network and industrial upgrading knowledge - centered approach. Working Paper No. 25, Economics Series, East-Wester Center, USA, 2001.

8. Abdon, A. and Felipe, J., The product space: what does it say about the opportunities for growth and structural transformation of Sub-Saharan Africa? Working Paper No 670, Levy Economics Institute of Bard College, NY, USA, 2011.

9. Li, C. and Syed, M., The shifting structure of China's trade and production. Working Paper No. 07-214, International Monetary Fund, Asia and Pacific Department, USA, 2007.

10. Wang, J., Some related concepts in China's research of industrial cluster. Acta Geogra. Sin., 2004, 59(S1), 47-52.

11. Hall, P., Innovation, Economics and Evolution: Theoretical Perspectives on Changing Technology in Economic Systems, Harvester Wheatsheaf, London, 1994

12. Lang, W. et al., Will affordability policy transcend climate change? A new lens to re-examine equitable access to healthcare in the San Francisco Bay Area. Cities, 2016, 58, 124-136.

13. Hausmann, R., Hwang, J. and Rodrik, D., What you export matters. J. Econ. Growth, 2007, 12(1), 1-25.

14. Felipe, J., Kumar, U., Usui, N. and Abdon, A., Why has China succeeded and why it will continue to do so. Cambridge J. Econ., 2013, 37, 791-818. 
15. Maskell, P. and Malmberg, A., Myopia, knowledge development and cluster evolution. J. Econ. Geogra., 2007, 7(5), 603-618.

16. Neffke, F., Henning, M. and Boschma, R., The impact of aging and technological relatedness on agglomeration externalities: a survival analysis. J. Econ. Geogra., 2011, 12(2), 485-517.

17. Farjoun, M., Beyond industry boundaries: human expertise, diversification and resource-related industry groups. Organ. Sci., 1994, 5, 185-199.

18. Fan, J. P. H. and Lang, L. H. P., The measurement of relatedness: an application to corporate diversification. J. Bus., 2000, 73(4), 629-660.

19. Boschma, R., Proximity and innovation: a critical assessment. Reg. Stud., 2005, 39(1), 61-74.

20. Balland, P. A., Boschma, R. and Frenken, K., Proximity and innovation: from statics to dynamics. Reg. Stud., 2015, 49(6), 907920.

21. Hidalgo, C. A., Klinger, B., Barabási, A. L. and Hausmann, R., The product space conditions the development of nations. Science, 2007, 317(5837), 482-487.

22. Hausmann, R. and Klinger, B., South Africa's export predicament. Working Paper No. 129, Kennedy School of Government, Harvard University, USA, 2006.

23. Hidalgo, C. A., The dynamics of economic complexity and the product space over a 42 year period. Working Paper No. 189, Center for international Development and Harvard Kennedy School, Harvard University, USA, 2009.

24. Cruz, J. and Riker, D., Product space analysis of the exports of Brazil. Working Paper No. 2012-06A, US International Trade Commission Office of Economics, USA, 2012.

25. Rizal, K., The evolution of regional industries in Indonesia: the roles of inter-product relatedness, 2017; https://www.researchgate. net/publication $/ 320466412$

26. Boschma, R. and Wenting, R., The spatial evolution of the British automobile industry: does location matter? Ind. Corporate Change, 2007, 16(2), 213-238.

27. Boschma, R., Minondo, A. and Navarro, M., The emergence of new industries at regional level in Spain: a proximity approach based on product relatedness. Econ. Geogr., 2012, 89(1), 29-51.
28. Boschma, R. and Iammarino, S., Related variety, trade linkages, and regional growth in Italy. Econ. Geogr., 2009, 85(3), 289-311.

29. Schumpeter, J. A., Capitalism, Socialism and Democracy, George Allen \& Unwin, Boston, MA, USA, 1942, 4th rev. edn.

30. Freeman, C. and Perez, C., Structural crises of adjustment, business cycles and investment behaviour. In Technical Change and Economic Theory, Pinter Publishers, London, UK, 1988.

31. Sydow, J., Lerch, F. and Staber, U., Planning for path dependence? The case of a network in the Berlin-Brandenburg optics cluster. Econ. Geogr., 2010, 86(2), 173-195.

32. Isaksen, A., Industrial development in thin regions: trapped in path extension? J. Econ. Geogr., 2015, 15(3), 585-600.

33. Young, A., The razor's edge: distortions and incremental reform in the People's Republic of China. Q. J. Econ., 2000, 115(4). 1091-1135.

34. Dawley, S., Creating new paths? Offshore wind, policy activism, and peripheral region development. Econ. Geogr., 2014, 90(1), 91-112.

35. Chen, Y. and Ye, L., A review of the research on identification method of industrial evolution. Econ. Res. Guide, 2009, 5, 44-47.

36. Lu, Y., Construction of Chinese national S\&T innovation system and latest advancements in science and technology in China. Curr. Sci., 2001, 81(8), 930-935.

37. Jin, B., Lv, T. and Deng, Z., Transformation and upgrading of China's industrial structure: process, issues and trends. China Ind. Econ., 2011, (2), 5-15.

ACKNOWLEDGEMENTS. We thank Prof. Yang Ruidai (School of Economics, Peking University, China) for providing source data for this study. We also thank Prof. Xu Xianxiang (Lingnan College, Sun Yat-Sen University, China) for guidance.

Received 3 November 2018; revised accepted 8 April 2019

doi: $10.18520 / \mathrm{cs} / \mathrm{v} 117 / \mathrm{i} 3 / 470-479$ 